\title{
Lokaal bestuur en burgerkracht: slimme sturing in het sociale domein*
}

\author{
Annie de Roo \& Rob Jagtenberg
}

\begin{abstract}
'Laat zorg en ondersteuning zoveel mogelijk aan de burgers zelf over. Dat bevordert hun autonomie en gevoel van verantwoordelijkheid voor elkaar. Tegelijkertijd maakt dat de zorg een stuk goedkoper.' Zo zou men de transformatie in zorg en welzijn kunnen samenvatten. Het lijkt een 'slimme' oplossing, maar hoe reëel zijn de aannames over de 'eigen kracht' van burgers met een zorgvraag? Zijn de huidige financiële en juridische sturingsinstrumenten toereikend om de gestelde beleidsdoelen te realiseren?

'Slim bestuur' in dit domein vereist primair inzicht in de factoren die bepalen wanneer een beroep op eigen kracht wel of niet werkt. Het betekent ook dat men zal moeten investeren in een wijze van besluitvorming die rekening houdt met alle betrokken belangen. Effectiviteit en legitimiteit blijken de twee belangrijkste randvoorwaarden voor 'slim bestuur'.
\end{abstract}

\section{Inleiding en vraagstelling}

Rond de eeuwwisseling openbaarde zich een groeiende onvrede over de 'lokettencultuur' die was ontstaan in zorg en welzijn, en de toenemende fragmentatie in het hulpverleningsaanbod. Een invloedrijk essay van de Raad voor Maatschappelijke Ontwikkeling (RMO), getiteld 'Burgerkracht - de toekomst van het sociaal werk in Nederland', concludeerde dat de zorgvragende burger gemarginaliseerd was door de toegenomen macht van overheid en markt (De Boer \& Van der Lans, 2011). Projecten op wijk- en buurtniveau waarbij burgers zelf weer aan zet komen, zo nodig met inzet van vrijwilligers in de kring om hen heen, werden als oplossingsrichting aangewezen. De zorgprofessional moest meer generalist worden, bij gezinnen achter de voordeur kijken ('erop af'), waardoor ook meer preventief gewerkt zou kunnen worden.

De mogelijkheid van kostenbesparing die in deze benadering besloten ligt, werd pregnant tijdens de financiële crisis en de daarmee samenhangende bezuinigingen op de zorguitgaven. Daarmee was het pleit voor een actieve rol van lokale netwerken beslecht en werd de 'zorgtransitie', na een minimale voorbereidingstijd, per 1 januari 2015 een feit.

* Dr. Annie de Roo is universitair hoofddocent bij Erasmus School of Law, hoofdredacteur van het Nederlands-Vlaams Tijdschrift voor Mediaton en Conflictmanagement (TMD) en projectleider van het NWO Slimme sturing project 'Lokaal bestuur en burgerkracht in Rotterdam' (2014-2019). Dr. Rob Jagtenberg is senior onderzoeker binnen het NWO project 'Lokaal bestuur en burgerkracht in Rotterdam' en was eerder betrokken bij diverse projecten inzake bestuur en ontwikkeling van o.a. de Wereldbank. 
Deze transitie omvat enerzijds een decentralisatie van verantwoordelijkheden op het gebied van maatschappelijke ondersteuning, jeugdzorg en arbeidsparticipatie naar de gemeenten; anderzijds omvat zij een verstrekkende transformatie: zorgprofessionals dienen voortaan de 'eigen kracht' van burgers en hun sociale omgeving voorop te stellen. De Wet maatschappelijke ondersteuning, de Jeugdwet en de Participatiewet vormen de basis voor deze ingrijpende operatie. De vier overkoepelende beleidsdoelstellingen die vooral aan de transformatie raken, zijn:

1 participatie (mensen moeten naar vermogen kunnen participeren in de samenleving);

2 integrale ondersteuning (één gezin, één plan, één regisseur);

3 'ont-zorgen' (minder specialistische zorg, ont-medicalisering, meer preventie); en

4 versterken van de eigen verantwoordelijkheid en zelfredzaamheid (de overheid is er alleen voor mensen die hun problemen niet op eigen kracht kunnen oplossen).

Voor deze hooggestemde verwachtingen bestaat nauwelijks een solide wetenschappelijke basis. Veelzeggend is dat er in de beleidstheorie rond de transformatie in de zorg eigenlijk geen sprake is van enige differentiatie, bijvoorbeeld naar gelang de aard van de zorgproblematiek, of naar gelang de omvang en samenstelling van ondersteunende netwerken. De aanname lijkt dat eigen (netwerk-)kracht overal zonder meer inzetbaar is. Ook de belangrijkste sturingsmechanismen, te weten subsidiëring en regulering, geven geen blijk van een voorafgaande bezinning op effectiviteit.

In deze bijdrage bespreken we de vele factoren die bepalend zijn voor een (duurzaam) beroep op de eigen kracht van burgers en hun netwerken. We doen dit op basis van bestaand internationaal onderzoek, en eerste inzichten uit ons eigen, nog lopende NWO-onderzoeksproject Lokaal bestuur en burgerkracht in Rotterdam. ${ }^{1}$ In het project worden factoren onderzocht op het microniveau van individuele zorgcliënten en hun omgeving. Wanneer bij grote aantallen zorgvragers de eigen kracht niet gemobiliseerd blijkt te (kunnen) worden, heeft dat immers directe repercussies voor de beleidstheorie.

Onze bevindingen nopen tot kritische kanttekeningen bij het realiteitsgehalte van de gestelde beleidsdoelen, en bij de effectiviteit van de huidige sturingsinstrumenten. Dit heeft als vanzelf gevolgen voor onze visie op wat nu eigenlijk 'slim bestuur' is in het sociale domein.

De opbouw van deze bijdrage is als volgt: eerst worden twee routes voor activering van burgers en hun netwerken besproken: de per ultimo 2015 van gemeentewege ingestelde wijkteams, die de spil vormen in het nieuwe zorgstelsel, en daarnaast de Eigen Kracht conferenties (EKc's), die als privaat initiatief van verontruste zorgprofessionals reeds een decennium vóór de eigenlijke zorgtransitie werden

1 Dit onderzoek wordt uitgevoerd in het kader van het NWO-onderzoekspogramma Smart Governance door de Erasmus School of Law (EUR) in samenwerking met de gemeente Rotterdam, de Eigen Kracht Centrale en het Centrum voor Dienstverlening. 
geïntroduceerd en door diverse provincies en gemeenten werden (en worden) gesubsidieerd.

De EKc's vielen tot 2015 buiten iedere regulering, maar vormen sindsdien een van de mogelijkheden om een nieuw recht inhoud te geven: het recht van de burger om samen met zijn netwerk een eigen plan te maken, waarop de professionele hulpverlening dient aan te sluiten. Behalve positief sanctionerend (door cliënten het recht op een eigen zorgplan toe te kennen) is de nieuwe regelgeving van 2015 ook negatief sanctionerend: gemeenten hebben slechts een voorzieningenplicht indien de eigen kracht van zorgvragers ontoereikend is.

Vervolgens worden belemmeringen geschetst die aan realisering van de gestelde beleidsdoelen, kortom participatie-gerichte sturing, in de weg lijken te staan. Daarbij gaat het niet alleen om factoren gelegen in de problematiek van zorgvragers, de samenstelling van hun netwerk en de relatie met de professional, welke sowieso medebepalend zijn voor een succesvol beroep op eigen (netwerk-)kracht. Ook belemmeringen die inherent zijn aan de sturingsinstrumenten subsidiëring en regulering in hun huidige opzet, zijn relevant. Tot slot worden ook machtgebonden belemmeringen besproken, die reeds eerder uit new governance-onderzoek (met name in de zorgsector) naar voren zijn gekomen.

De gevolgtrekkingen uit de besproken belemmeringen voor onze opvatting van 'slim bestuur' vormen het onderwerp van de slotparagraaf.

\section{Routes en sturingsinstrumenten}

\section{Routes: wijkteams en Eigen Kracht conferenties}

Chronologisch gezien dient deze impressie van routes voor netwerk-activering te beginnen bij de Eigen Kracht conferenties. Al vóór de eigenlijke transitie formeel haar beslag kreeg, was bij zorgprofessionals zelf onvrede ontstaan. Deze professionals richtten in 2000 de 'Eigen Kracht Centrale' op, een particulier initiatief om de leefwereld en de eigen regie van de zorgvragende burger en zijn sociale omgeving centraal te stellen, en niet de systeemwereld van de overheid. Het daartoe ingezette besluitvormingsmodel was, en is, de 'Eigen Kracht conferentie', ontleend aan de tien jaar eerder in Nieuw-Zeeland geïntroduceerde family group conference (De Roo \& Jagtenberg, 2017).

Een dergelijke conferentie wordt samen met het sociale netwerk van de zorgvragers georganiseerd. De praktische voorbereiding ligt bij een onafhankelijke procesbegeleider, de coördinator, die voor de familie acceptabel is en 'hun taal' spreekt. Deze coördinator neemt de vaak tijdrovende taak op zich om het sociale netwerk dat steun zou kunnen bieden in kaart te brengen, de leden uit te nodigen voor een gezamenlijke bijeenkomst, en eventuele obstakels voor zo'n samenkomst (bijvoorbeeld door onderlinge ruzies en wantrouwen) waar mogelijk vooraf weg te nemen.

Wanneer een conferentie belegd is, treedt de coördinator op als gespreksleider. Nadat de zorgprofessional heeft meegedeeld waar zijns inziens acute zorgpunten liggen, verlaat deze met de coördinator de bijeenkomst, en blijven de familieleden 
c.q. de leden van het eigen sociale netwerk achter om samen een plan te bedenken en die zorgpunten weg te nemen.

Wanneer een zorgprofessional bijvoorbeeld een uithuisplaatsing van een verwaarloosd kind in het vooruitzicht stelt, kunnen een aanwezige oom en tante besluiten de opvoeding van het betrokken kind van de falende ouder(s) over te nemen, en kunnen een neef en een vriend van de ouder(s) hun hulp aanbieden om het leven van die ouder(s) weer op de rails te krijgen. Wordt het plan geaccepteerd, dan dient eventuele verdere professionele ondersteuning vanuit de overheid op het plan van het eigen netwerk te zijn gebaseerd.

De confrontatie van netwerkleden met elkaar, en met een urgent probleem dat wellicht eerder verzwegen werd, vormt, vooral door de ingebouwde private network time, bij uitstek een model waarbij burgers zelf in actie moeten komen, op basis van hun eigen creativiteit en inzicht in prioriteiten.

Hoewel de conferenties niet altijd succesvol zijn, lijkt de eigen kracht van zorgvragers door deze insteek per saldo te zijn toegenomen (Oosterkamp-Szwajcer \& De Swart, 2012). Vanuit het openbaar bestuur bezien lijken dergelijke conferenties voor de beoogde participatiesamenleving daarom een interessant sturingsmiddel op microniveau.

Aan de organisatie van Eigen Kracht conferenties zelf zijn echter kosten verbonden, voornamelijk voor de werkzaamheden van de onafhankelijke coördinator. Daartoe hebben sommige provincies (vóór 2015) en sommige gemeenten (vanaf 2015) subsidies verstrekt.

Behalve de overheid dient ook een andere actor ruimte te bieden aan dergelijke conferenties, te weten: de zorgprofessional. Op de zogeheten participatie-ladder van Arnstein gaat het hier om meer dan alleen consultatie van het sociale netwerk. Het netwerk participeert als een volwaardige partner van de (door de overheid bekostigde) zorgprofessional voor wat betreft de keuze van verdere acties (Clarijs, 2012). Men kan hier daarom van collaborative, of participatory governance op microniveau spreken (Ansell, 2012; Fischer, 2012). Een dergelijke 'samenwerking' tussen zorgvrager en professional vereist wel dat deze laatste een doctor-knowsbest-houding moet laten varen.

Sinds 2015 opereert die zorgprofessional 'in de eerste lijn' via de wijkteams. De transitiewetgeving heeft de gemeenten weliswaar een voorzieningenplicht opgelegd, maar de feitelijke organisatie van de zorg- en hulpverlening aan de gemeenten zelf overgelaten. Fascinerend is dat vrijwel alle gemeenten hiervoor het wijkteammodel hebben geïntroduceerd, hoewel hiermee vóór 2015 op slechts beperkte schaal ervaring was opgedaan (Winter, 2015; zie ook Oldenhof \& Bal, 2014).

Doorgaans bestaan de wijkteams uit enkele gemeenteambtenaren en een - op het ressort afgestemde - mix van professionele hulpverleners die vanuit zorgaanbieders naar het wijkteam zijn gedetacheerd. Het werken in teamverband tussen professionals die voorheen ieder hun eigen methodieken hanteerden en elkaar daarmee beconcurreerden, vergde aanvankelijk de nodige energie. 
De wijkteamprofessionals worden geacht - waar mogelijk - de burger en diens eigen (netwerk-)kracht te activeren. Dat kan door verwijzing naar een Eigen Kracht conferentie (wanneer gemeenten die hebben ingekocht), maar de professional kan ook zelf een beraad met familie en vrienden van de zorgcliënt organiseren. Volledigheidshalve: de wijkteamprofessional kan ook - indien noodzakelijk specialistische hulpverlening (tweedelijns zorg) indiceren.

\section{Sturingsinstrumenten: subsidiëring en regulering}

In verband met de nieuwe taken steeg het totale budget voor de gemeenten weliswaar van 20 naar 30 miljard euro, maar voor de uitvoering van die nieuwe taken is effectief veel minder geld beschikbaar dan voorheen voor Rijk en provincie.

Het potentieel aan eigen burgerkracht diende dus kordaat te worden geëffectueerd en de transitiewetgeving voorziet daartoe in zowel negatief-sanctionerende als positief-sanctionerende regulering. $\mathrm{Zo}$ is de voorzieningenplicht van de gemeenten voortaan geconditioneerd: eerst dient het eigen probleemoplossend vermogen van de burger en diens netwerk te worden aangesproken. Positief-sanctionerend is dat aan zorgvragers een recht op een 'eigen plan' (de Wmo) dan wel een 'familiegroepsplan' (de Jeugdwet) is toegekend. Het familiegroepsplan is niet identiek aan een Eigen Kracht conferentie, zo blijkt uit een factsheet van de Vereniging van Nederlandse Gemeenten (VNG). Zo'n familiegroepsplan kan door families zelf worden opgesteld, bijvoorbeeld door een Eigen Kracht conferentie, maar dit kan ook gebeuren in een beraad onder leiding van de zorgprofessional c.q. de wijkteams (VNG, 2014).

\section{Effectiviteit; belemmeringen voor participerende sturing}

\section{Factoren die duurzame eigen (netwerk-)kracht medebepalen}

Een fundamentele vraag is of er altijd en overal een beroep op eigen (netwerk-)kracht kan worden gedaan. Uit systematische reviews en lopend eigen onderzoek blijkt dat veel factoren een succesvol beroep op eigen (netwerk-)kracht kunnen bepalen. Naast persoonlijke achtergrondkenmerken van zorgvragers en de aard en duur van hun problematiek spelen ook de omvang en samenstelling van eigen netwerken, de beroepshouding van de zorgprofessional en de al dan niet bestaande 'klik' tussen hulpverlener en zorgvragers een rol. Ook beschikbare (financiële) hulpbronnen en stimulerende regelgeving zijn van belang. Vooral deze laatste twee aspecten lijken hier interessant, omdat zij raken aan de huidige sturingsinstrumenten.

\section{Subsidiëring/budgettering: catch 22?}

Zijn de wijkteams nu ook dichter bij de burger komen te staan, zodat gezamenlijke regie en activering van de netwerken rond zorgvragers, niet slechts via Eigen Kracht conferenties maar ook door de wijkteam-medewerkers zelf, uit de verf kunnen komen? Een in 2016 opgemaakte tussenbalans laat een zorgelijk beeld zien (Kruiter, Bredewold, \& Ham, 2016). Het blijkt onduidelijk hoe de wijkteams die doelen moeten realiseren. Een groot euvel blijkt de werkdruk: hoe dichter 
wijkteamleden de zorgvragers benaderen, hoe meer zij dreigen te verdrinken in de complexiteit van de problemen.

De financiële kaders lijken daarbij een fundamenteler obstakel dan de vereiste cultuuromslag bij de zorgprofessionals; dat is althans onze voorlopige indruk uit het nog lopende onderzoek onder wijkteams in Rotterdam. Kort gezegd: de meeste wijkteams zouden zorgvragers en hun netwerk wel bij de hulpverlening willen betrekken, maar hebben eenvoudig niet de personele middelen en de tijd om zulke netwerken in kaart te brengen, laat staan de leden ervan te benaderen en goed voor te bereiden voor een beraad. Een coördinator van Eigen Kracht conferenties heeft die tijd wel (gemiddeld blijkt hiermee algauw 25 uur gemoeid), maar ook de middelen voor zulke EKc's worden (of zijn al) drastisch beperkt.

Toch laat onderzoek zien dat daar waar een netwerk succesvol participeert, dit tot besparingen kan leiden. De publiek bekostigde professional kan dan immers gerichter werken. Pas als men daadwerkelijk investeert in netwerk-activering (via wijkteams dan wel EKc's) kan dit - onder voorwaarden - besparingen opleveren. Welbeschouwd: een catch 22-situatie.

\section{Regulering: toch de zorgprofessional centraal?}

Hoe is het gesteld met het recht van zorgvragers en hun netwerk om zelf een plan te maken, waarop de professional dient aan te sluiten? Om te beginnen blijkt dit nieuwe recht nog weinig bekend, ook onder de zorgprofessionals. Waar zorgvragers dankzij enkele goed ingevoerde advocaten dit recht toch ontdekken en voor de rechter inroepen tegen de zorgprofessional, blijkt de rechter in overwegende mate op het oordeel van de professional te vertrouwen en wordt de burger niet gevolgd.

Ook op basis van de negatief-sanctionerende regulering (conditionering van de voorzieningenplicht) zijn diverse zorgvragers naar de rechter gestapt. Voorlopig sluitstuk vormde de uitspraak in een beroep tegen de gemeente Steenwijkerland uit 2017, waarin de hoogste bestuursrechter oordeelde dat een gemeente alleen dan een beroep op de eigen kracht van een zorgvrager (en diens netwerk) mag doen, wanneer eerst een gekwalificeerde zorgprofessional heeft vastgesteld dat in de voorliggende kwestie geen specifieke deskundigheid vereist is. Alleen de professional kan beoordelen of professionele hulp vereist is, of niet. Vooralsnog lijkt het er dus op dat wat de overheid met de ene hand aan regierechten overhevelt van zorgprofessional naar burger, zij met de andere hand (de rechter) weer terug hevelt naar diezelfde professional.

\section{Afhankelijkheid en machtsbalans}

Bij dit alles moet men bedenken dat de zorgvrager voor hulp veelal afhankelijk is van de zorgprofessional, waardoor sprake is van een machtsonbalans. Yishai toonde voor de medische sector aan dat de (daar nog grotere) patiënt-afhankelijkheid ertoe heeft geleid dat patiëntenorganisaties in het maatschappelijk middenveld (met name in Nederland) niet daadwerkelijk participeren in besluitvorming, zelfs niet in zaken die geen vakspecifieke expertise vereisen. Het lijkt evident dat hier een serieuze barrière ligt voor het effectief gebruik van regels die participatie beogen te bevorderen (Yishai, 2012). 


\section{Afronding: 'slim bestuur' in het sociale domein}

De verwachtingen waren hooggestemd: autonomie en gezamenlijke verantwoordelijkheid van burgers zouden gestimuleerd kunnen worden met een gereduceerd zorgbudget. Daarvoor zou slechts nodig zijn dat de zorgvragers en hun netwerk vrijwillig taken overnemen van de publiek bekostigde professionals. Uit onderzoek blijkt dat er situaties bestaan waarin effectieve samenwerking tussen professional en zorgvragers en hun netwerk tot stand komt en rendeert; maar er zijn evenzeer situaties waarin samenwerking niet of nauwelijks van de grond komt. Hier zijn vele factoren in het spel. De in het NWO-onderzoek nog uit te voeren statistische analyses kunnen hopelijk duidelijkheid verschaffen over oorzakelijke samenhangen. Daarmee kan de mogelijkheid van evidence-based beleid een stap dichterbij worden gebracht.

Echter: in die gevallen waarin de randvoorwaarden voor succesvolle activering aanwezig lijken, zullen de sturingsinstrumenten subsidiëring en regulering nog niet automatisch tot resultaat leiden. Dat komt door de besproken onduidelijkheden en belemmeringen die inherent zijn aan deze sturingsinstrumenten in hun huidige opzet.

Voor wat betreft subsidiëring: de RMO had in het rapport 'Leren innoveren in het sociaal domein' (RMO, 2014) gesteld: 'Stuur maatschappelijke organisaties niet op output, maar op de mate waarin ze maatschappelijke doelen realiseren (...), en biedt burgers en organisaties de ruimte om te experimenteren en daardoor te leren innoveren.'

Die ruimte lijkt echter volledig te ontbreken: wijkteams zelf klagen over hun werkdruk en de budgettaire ruimte voor Eigen Kracht conferenties wordt alom gereduceerd. Toch lijkt het evident dat men tijd zal moeten investeren om potentiële netwerkleden bij de besluitvorming te betrekken, wil men het potentieel van de 'netwerkfactor' goed kunnen inschatten en benutten. Bovendien lijkt ons een dergelijk betrekken bij de besluitvorming niet alleen een eis van effectiviteit, maar ook een eis van legitimiteit. Immers: vrijwilligers uit een netwerk, zoals mantelzorgers, 'betalen' de zorg, niet met belastinggeld, maar in de vorm van door hen ingeleverde tijd. Dergelijke (maatschappelijke) kosten en 'waterbedeffecten' ontbreken vaak in neoklassieke efficiency-berekeningen. De new economics-beweging heeft zich ten doel gesteld om dergelijke verborgen dimensies weer op de kaart te zetten en hun prijs te berekenen (Nicholls, Lawlor, Neitzert \& Goodspeed, 2012). Voor zover onder 'slim bestuur' in het sociale domein ook 'efficiënt bestuur' begrepen wordt, moet men zich er eerst rekenschap van geven wiens kosten (en op welke termijn) in de efficiency-vergelijking zijn meegenomen. Als dit slechts streng begrote, korte termijn kosten voor de schatkist zijn, is het onwaarschijnlijk dat er ooit significante baten zullen volgen.

Tot slot het sturingsinstrument regulering. De huidige regels lijken hun doel niet te kunnen bereiken omdat burgers met deze regels (met name de positief-sanctionerende) onbekend zijn, en/of omdat de rechter de regels (met name de negatiefsanctionerende) neutraliseert door het primaat bij de zorgprofessional terug te 
leggen, waarschijnlijk ook ter redressering van de machtsonbalans. Dat is op zich verdedigbaar. Toch zou dit sturingsinstrument beter aan zijn doel kunnen beantwoorden, wanneer ten minste meer bekendheid aan het bestaan van de regels zou worden gegeven en rechters meer aandacht zouden hebben voor inzet op (herstel van de vaak verstoorde) communicatie tussen zorgprofessional en zorgvragende.

Kortom: 'slim bestuur' in het sociale domein zal pas dan 'slim' kunnen zijn, wanneer meer bekend is over de factoren die voor de inzet van eigen (netwerk-)kracht bepalend zijn, en na een kritische reflectie op (en aanpassing van) de huidige sturingsinstrumenten subsidiëring en regulering, zodanig dat aan de randvoorwaarden 'effectiviteit' en 'legitimiteit' wordt voldaan.

\section{Literatuur}

Ansell, Ch. (2012). Collaborative governance. In D. Levi-Faur (Ed.), Oxford handbook of governance (pp. 498-511). Oxford: Oxford University Press.

Boer, N. de, \& Lans, J. van der. (2011). Burgerkracht: de toekomst van het sociaal werk in Nederland. Den Haag: RMO.

Clarijs, R. (2012). Family Group Conferences as cause and effect of people power. In R. Clarijs \& Th. Malmberg (Eds.), The quiet revolution aggrandising people power by FGC's (pp. 83-105). Amsterdam: SWP Publishers.

Fischer, F. (2012). Participatory governance: from theory to practice. In L.-F. David (Ed.), Oxford handbook of governance (pp. 457-471). Oxford: Oxford University Press.

Kruiter, A.J., Bredewold, F., \& Ham, M. (2016). Hoe de Verzorgingsstaat verbouwd wordt Kroniek van een verandering. Amsterdam: van Gennep.

Nicholls, J., Lawlor, E., Neitzert, E., \& Goodspeed, T. (2009). A guide to social return on investment. London: Cabinet Office.

Oldenhof, L., \& Bal, R. (2014). Wijkgovernance 'in the making': het verplaatsen van zorg en ondersteuning naar wijken. Rotterdam: IBMG.

Oosterkamp-Szwajcer, E.M., \& Swart, J.J.W. de. (2012). Op Eigen Kracht vooruit - Een onderzoek naar de resultaten van Eigen Kracht-conferenties in Nederland. Enschede: Saxion.

RMO (Raad voor Maatschappelijke Ontwikkeling). (2014). Leren innoveren in het sociaal domein. Den Haag: RMO.

Roo, A. de, \& Jagtenberg, R. (2017). Naar een regierecht voor de burger in het sociale domein? Het recht op een familiegroepsplan als legal transplant. Recht der Werkelijkheid, 38(2), 9-28.

VNG. (2014). Factsheet het Familiegroepsplan. Online beschikbaar op https://vng.nl.

Winter, H. (2015). Bestuurlijke organisatie en geschilbeslechting in het sociaal domein. Groningen: Rijks universiteit Groningen.

Yishai, Y. (2012). Participatory governance in public health: choice, but no voice. In L.-F. David (Ed.), Oxford handbook of governance (pp. 527-536). Oxford: Oxford University Press. 